
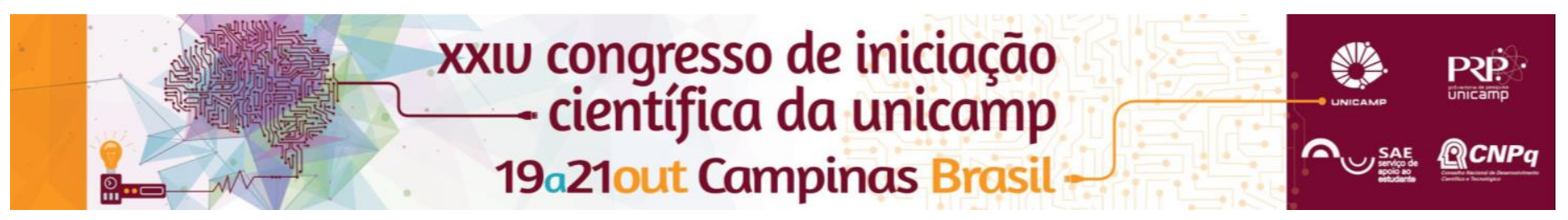

\title{
Estudo da Transmissão Continuamente Variável Industrial: Simulação e Bancada Experimental.
}

\author{
Aluno: Enzo Saquetti Bernardinelli \\ Orientadora: Drª Ludmila Corrêa Alkmin e Silva
}

\section{Resumo}

As transmissões são amplamente utilizadas tanto na indústria quanto na vida quotidiana das pessoas. Existem dois principais tipos, as escalonadas simples (amplamente difundida) e as transmissões continuamente variável (CVT's). Esta última tem uma vantagem sobre as demais, sua eficiência na transmissão das rotações do motor para o restante do sistema é maior. Como resultado chegou-se à uma melhor compreenção de como se dá o funcionamento dinâmico da CVT e os principais parâmetros a serem definidos para o projeto de uma CVT.

\section{Palavras-chave:}

CVT, transmissão, eficiência

\section{Introdução}

Desde o surgimento dos motores houve a necessidade do uso de sistemas de redução, principalmente para que se permitisse um melhor do regime de operação destes motores, através das relações (entre entrada e saída) da transmissão.

O desenvolvimento das transmissões variáveis tem como principal campo o setor automotivo. Durante anos surgiram vários tipos de transmissões, sendo a principal delas a Escalonada Simples (usada na maioria dos veículos de transmissão manual hoje em dia) (Raizer, 2010). O principal motivo dela ainda ser utilizada em larga escala é o fato de ser bem compreendido seu funcionamento e de sua fabricação já ser dominada pela indústria.

A CVT varia da relação de transmissão da mais reduzida para a mais alta sem que haja desacoplamento do motor e assim aproveitando ao máximo a potência por ele fornecida (aumento da eficiência do sistema mecânico) (Genta, 2006).

Este trabalho foi motivado pelo fato de entender melhor como se dá o dimensionamento de uma CVT por correia metálica, para que posteriormente possa ser montada uma bancada de testes.

\section{Resultados e Discussão}

Após um estudo aprofundado para compreender como se dão as relações geométricas de uma CVT por correia metálica, chegou-se às seguintes relações:

$$
L=R p . \beta p+\text { Rsec. } \beta s e c+2 \cdot \sqrt{ }\left(X^{2}-(\text { Rsec-Rp })^{2}\right)
$$

L: Comprimento da correia, X: Entre eixo das polias (140 $\mathrm{mm})$

$$
\begin{aligned}
& \alpha p=\operatorname{arcsen}((\text { Rsec-Rp }) / X) \\
& \beta p=\pi-2 . \alpha p \\
& \beta s e c=\pi+2 . \alpha p
\end{aligned}
$$

Define-se ap como o ângulo que a correia faz com a horizontal, $\beta p$ o ângulo de abraçamento da correia com a polia motora e ßsec o ângulo de abraçamento da correia com o polia movida.

Para as medidas que retiramos da desmontagem da CVT, temos:

$$
\alpha p=0,297, \beta p=2,547, \beta s e c=3,736
$$

DOI: 10.19146/pibic-2016-51574
Chegando a um valor do comprimento da correia de $L=609,385 \mathrm{~mm}$. Com isso Podemos perceber no gráfico abaixo como variam os raios (Rp e Rsec) ao longo das relações de transmissão.

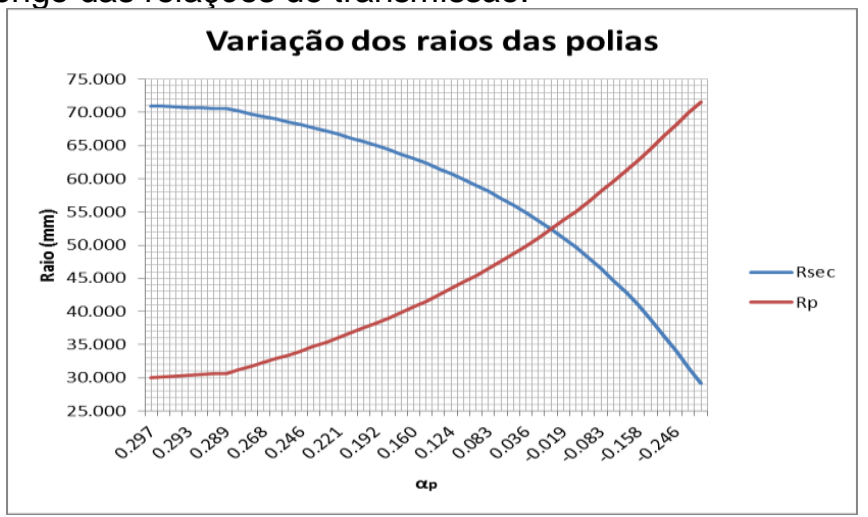

Figura 1 - Variação dos raios das polias da CVT por correia metália em estudo

\section{Conclusões}

Como resultado chegou-se à uma melhor compreenção de como se dá o funcionamento dinâmico da CVT e os principais parâmetros a serem definidos para o projeto de uma CVT por correia metálica.

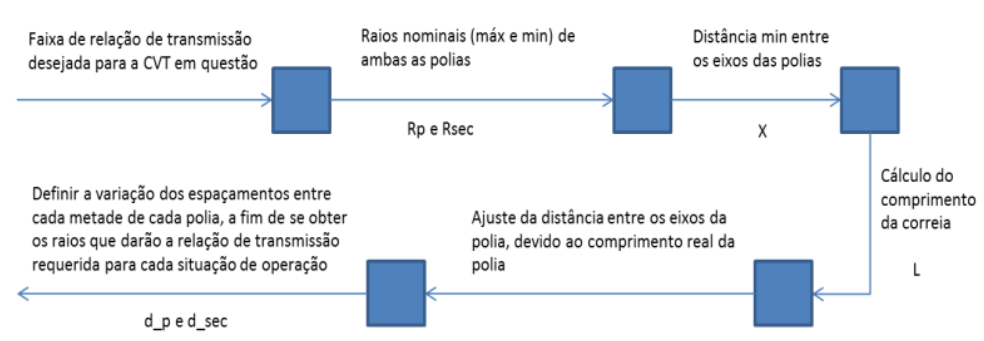

Figura 2 - Fluxograma de definição dos parâmetros geométricos de uma CVT

\section{Bibliografia}

Genta, Giancarlo (2006) "Motor Vehicle Dynamics Modeling and Simulation", Editora World Scientifc.

Raizer, Breno (2010) "Modelagem e Análise Cinemática de CVT"s Toroidais: Influência dos parâmetros geométricos no desempenho." Tese de Mestrado FEM-UNICAMP. 